\title{
Perbandingan Otsu Dan Iterative Adaptive Thresholding Dalam Binerisasi Gigi Kaninus Foto Panoramik
}

\author{
Nur Nafi'iyah', Retno Wardhani ${ }^{2}$ \\ Teknik Informatika, Fakultas Teknik Universitas Islam Lamongan \\ Email: ${ }^{1}$ nafik_unisla26@yahoo.co.id, ${ }^{2}$ retzno@yahoo.com
}

\begin{abstract}
ABSTRAK. Proses binerisasi bertujuan untuk memudahkan pengenalan citra dalam tahap computer vision. Binerisasi merupakan cara mengubah bentuk warna citra ke hitam putih atau biner. Metode otsu merupakan metode konversi citra ke bentuk hitam putih. Metode iterative dan adaptive thresholding merupakan gabungan metode dalam mengubah citra ke biner. Tujuan dari penelitian ini, yaitu: memudahkan dalam tahap ekstraksi citra atau pengambilan informasi terpenting dalam citra. Sehingga proses selanjutnya seperti pengenalan citra atau recognition. Hasil dari penelitian ini berupa citra biner gigi kaninus foto panoramik. Dari perbandingan metode, metode iterative dan adaptive thresholding menghasilkan gambar biner yang lebih baik.
\end{abstract}

Kata Kunci: Otsu, Iterative dan Adaptive Thresholding, Foto Panoramik Gigi Kaninus.

\section{PENDAhuluan}

Pengolahan citra (image processing) merupakan suatu sistem di mana proses dilakukan dengan masukan berupa citra (image) dan hasilnya juga berupa citra (image). Pada awalnya pengolahan citra ini, dilakukan untuk memperbaiki kualitas citra, namun dengan berkembangnya dunia komputasi yang ditandai dengan semakin meningkatnya kapasitas dan kecepatan proses komputer, serta munculnya ilmu-ilmu komputasi yang memungkinkan manusia dapat mengambil informasi dari suatu citra, maka image processing tidak dapat dilepaskan dengan bidang computer vision.

Salah satu bidang yang menggunakan pengolahan citra yang saat ini banyak dikembangkan orang adalah biometric, yaitu bidang yang mempelajari bagaimana dapat mengidentifikasi seseorang dengan ciri yang unik yang ada dalam tubuh manusia. Salah satunya adalah identifikasi gigi geligi, yang merupakan ciri unik yang dapat membedakan orang yang satu dengan yang lainnya. Untuk melakukan identifikasi gigi geligi diperlukan pengolahan citra untuk melakukan capture (penangkapan citra gigi, dengan istilah dental radiograph), sampai pada ekstraksi ciri, yaitu mengekstrak besaran-besaran numerik yang dapat dijadikan suatu ciri gigi seperti lengkung rahang dan jumlah gigi dan lainnya, yang pada akhirnya dilakukan proses pembelajaran agar komputer dapat secara tepat mengidentifikasi manusia berdasarkan foto gigi.

Dalam perkembangan lebih lanjut dari ilmu komputasi yang memanfaatkan pengolahan citra, ternyata untuk mengidentifikasikan seseorang tidak hanya dengan gigi geligi, tetapi dapat juga dilakukan dengan pengenalan wajah (face recognition) atau pengenalan iris mata (iris recognition) dan sidik jari. Dalam model pengenalan wajah dan pengenalan iris, proses pengolahan citra yang dilakukan menjadi tidak sederhana, baik dari sisi capture atau pengambilan citra, sampai pada ekstraksi cirinya. Pada pengenalan wajah proses capture ini sangat menentukan tingkat kesulitan dalam komputasinya, salah satunya bahwa dalam setiap proses capture ternyata cahaya, warna, posisi, skala dan kemiringan menjadi suatu masalah yang perlu diperhatikan.

Oleh karena itu, dalam tingkatan yang sulit ini, peneliti melakukan percobaan untuk mengolah citra gigi panoramik dalam mengubah ke bentuk biner. Agar dapat dimanfaatkan dalam identifikasi forensik atau dalam pengenalan seseorang yang belum dikenal.

Adapun tujuan dari penelitian ini, yaitu memudahkan proses selanjutnya dalam pengenalan atau identifikasi manusia berdasarkan foto panoramik gigi. Manfaatnya agar dapat memudahkan pengambilan ekstraksi fitur atau informasi dari foto panoramik gigi.

1. Foto Panoramik dan Gigi Kaninus

Dental radiograph (umumnya merujuk pada film $X$-ray) adalah gambaran dari gigi, tulang, dan bagian lunak yang berada di sekitarnya untk melindungi dan membantu mengidentifikasi masalah dengan gigi, mulut, dan rahang. Gambar $x$-ray dapat menampilkan lubang, sel yang bersifat kanker atau massa yang lunak, struktur gigi yang tersembunyi (seperti gigi wisdom), dan kehilangan tulang yang tidak dapat dilihat selama pemeriksaan visual. $X$-ray dapat juga dilakukan sebagai tindak lanjut setelah perawatan gigi.

Sebuah citra radiografis dibentuk dengan sebuah ledakan radiasi $x$-ray terkontrol yang menembus struktur mulut dengan level-level berbeda, bergantung pada variasi kepadatan anatomis, sebelum mengenai film atau sensor. Gigi tampak lebih terang karena radiasi yang menembusnya lebih sedikit untuk mencapai film. Pembusukan tulang gigi, pembusukan gigi, infeksi dan perubahan lainnya dalam intensitas tulang, dan ligamen periodontal tampak lebih gelap karena $x$-ray telah menembus struktur yang kurang tebal tersebut. Restorasi gigi 
(tambalan gigi, mahkota gigi) mungkin tampak lebih terang atau lebih gelap bergantung pada kepadatan material tersebut.

Orang yang pertama kali menggunakan radiografi adalah W.G.Morton di Amerika pada tahun 1896, kemudian C. Edmund Kells adalah dokter gigi pertama yang menganjurkan penggunaan radiografi secara rutin pada praktek dokter gigi. Foto radiografi adalah gambaran dua dimensi dari suatu obyek tiga dimensi di mana gambaran dari obyek tersebut diproyeksikan pada suatu media perekam sebagai gambar dua dimensi.

Secara umum radiografi dapat digunakan untuk memeriksa struktur yang tidak terlihat pada pemeriksaan klinis. Kegunaan foto Rontgen gigi yaitu:

a. Untuk mendeteksi lesi

b. Untuk membuktikan suatu diagnosa penyakit.

c. Untuk melihat lokasi lesi/benda asing yang terdapat pada rongga mulut.

d. Untuk menyediakan informasi yang menunjang prosedur perawatan.

e. Untuk mengevaluasi pertumbuhan dan perkembangan gigi geligi.

f. Untuk melihat adanya karies, penyakit periodontal dan trauma.

g. Sebagai dokumentasi data rekam medis yang dapat diperlukan sewaktu waktu.

Secara garis besar foto rontgen gigi, berdasarkan teknik pemotretan dan penempatan film, dibagi menjadi dua bagian, yaitu:

1) Teknik radiografi intra oral, merupakan pemeriksaan gigi dan jaringan sekitar secara radiografi dan filmnya ditempatkan di dalam mulut pasien selama penyinaran. Radiografi intra oral terdiri dari foto periapikal, foto bite wing, dan foto oklusal.

2) Teknik radiografi ekstra oral, merupakan radiografi yang digunakan untuk melihat area yang luas pada rahang dan tengkorak yang mana film yang digunakan diletakkan di luar mulut. Foto Rontgen ekstra oral yang paling umum dan paling sering digunakan adalah foto Rontgen panoramik, sedangkan contoh foto Rontgen ekstra oral lainnya adalah foto lateral, foto antero posterior, foto postero anterior, foto cephalometri dan lain-lain.

Radiografi panoramik adalah teknik radiografi ekstra oral yang dapat memperlihatkan rahang atas dan rahang bawah sekaligus, serta struktur anatomis yang berdekatan dalam satu film. Teknik radiografi ini digunakan untuk pemeriksaan, diagnosis, dan memilih jenis perawatan yang terbaik serta sebagai alat screening/seleksi dan penilaian menyeluruh (radiografi studi). Gambar 1 merupakan foto panoramik, cara pengambilan gambarnya melalui ekstra oral.

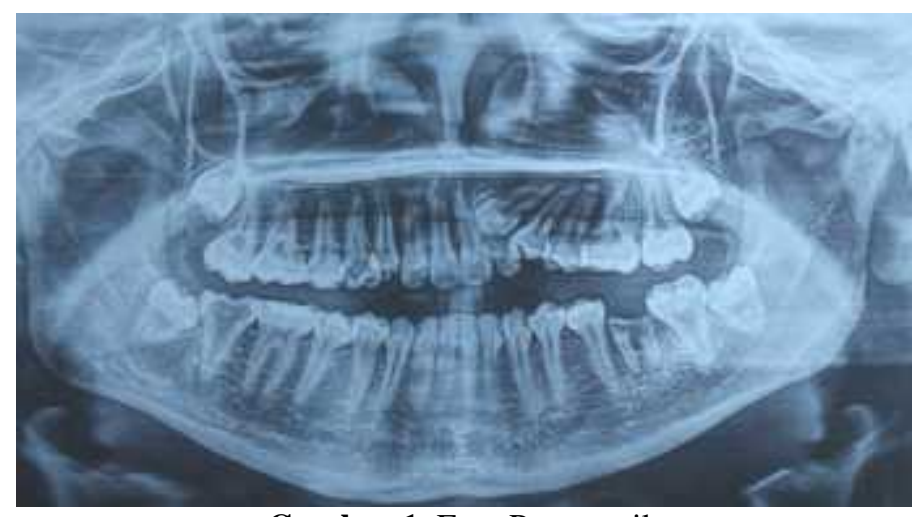

Gambar 1. Foto Panoramik

Dalam foto panoramik terlihat jelas, bahwa gigi orang dewasa yang permanen sebanyak 32 gigi tetap. Yang susunannya 16 gigi di rahang atas (maksila), dan 16 gigi di rahang bawah (madibula). Dalam rahang atas terdapat 8 gigi sebelah kiri, dan 8 gigi sebelah kanan, adapun dalam rahang bawah juga seperti itu. Ditunjukkan dalam tabel berikut.

\begin{tabular}{l|l}
87654321 & 12345678 \\
\hline 87654321 & 12345678
\end{tabular}

Nama dari macam-macam gigi permanen, adalah:

1 Gigi seri pertama/insisivus sentral

2 Gigi seri kedua/insisivus lateral

3 Gigi taring/gigi kaninus

4 Gigi geraham kecil pertama/premolar 1

5 Gigi geraham kecil kedua/premolar 2

6 Gigi geraham besar pertama/molar 1 
7 Gigi geraham besar kedua/molar 2

8 Gigi geraham besar ketiga/molar 3

\section{Pengolahan Citra}

Hubungan image processing dengan pembagian bidang dalam komputer yang melibatkan input dan output tertentu dapat dilihat pada Tabel 1. Dalam Tabel 1 terlihat bahwa pengolahan citra (image processing) merupakan suatu bidang pengetahuan di mana inputnya berupa citra dan hasilnya juga berupa citra dengan proses yang berupa perbaikan baik kualitas citra atau penyajian informasi citra. Agar hasilnya berupa data numerik atau teks yang menyatakan informasi yang ada dalam citra diperlukan pengetahuan yang dipelajari dalam pattern recognition dan computer vision.

Tabel 1. Bidang Komputer dalam Citra

\begin{tabular}{|c|c|c|c|}
\hline \multirow{3}{*}{ Input } & & \multicolumn{2}{|c|}{ Output } \\
\cline { 2 - 4 } & Image & Image & Deskripsi \\
\cline { 2 - 4 } & Deskripsi & Computer Graphics & Pattern Recognition, Computer \\
& & & Vision \\
\hline
\end{tabular}

Proses pengolahan citra secara diagram proses dimulai dari pengambilan citra, perbaikan kualitas citra, sampai dengan pernyataan representatif citra digambarkan seperti Gambar 2.

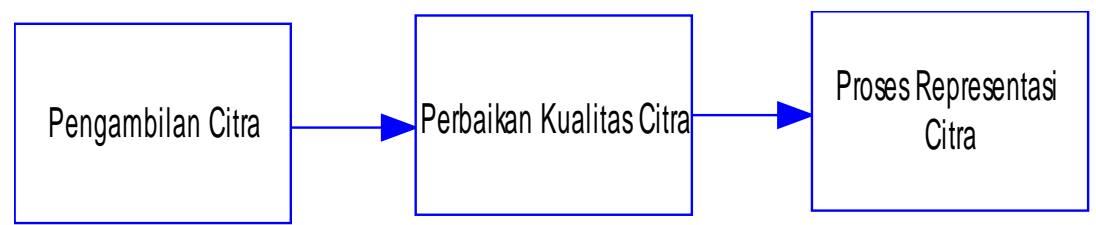

Gambar 2. Proses Pengolahan Citra

Secara umum teknik pengolahan citra digital dibagi menjadi 3 tingkat pengolahan, yaitu:

1) Tahap 1 yang dinamakan dengan Low-Level Processing (pengolahan tingkat rendah). Pengolahan ini operasional-operasional dasar dalam pengolahan citra, seperti pengurangan noise (noise reduction), perbaikan citra (image enhancement) dan restorasi citra (image restoration).

2) Tahap 2 yang dinamakan dengan Mid-Level Processing (pengolahan tingkat menengah). Pengolahan ini meliputi segmentasi pada citra, deskripsi objek, dan klasifikasi objek secara terpisah.

3) Tahap 3 yang dinamakan dengan High-Level Processing (pengolahan tingkat tinggi), yang meliputi analisis citra.

Dari ketiga tahap pengolahan citra digital di atas, dapat dinyatakan suatu gambaran mengenai teknik-teknik pengolahan citra digital dan macam-macamnya antara lain:

1) Image Enhancement, berupa proses perbaikan citra dengan meningkatkan kualitas citra baik kontras maupun kecerahan.

2) Image Restorasi, proses memperbaiki model citra, biasanya berhubungan dengan bentuk citra yang sesuai.

3) Color Image Processing, suatu proses yang melibatkan citra berwarna, baik berupa image enhancement, image restoration, atau yang lainnya.

4) Wavelet dan Multiresolution Processing, merupakan suatu proses yang menyatakan citra dalam beberapa resolusi.

5) Image Compression, merupakan proses yang digunakan untuk mengubah ukuran data pada citra. Saat ini, proses ini terus dikembangkan. JPEG-4 merupakan salah satu bentuk image compression yang baik dan saat ini banyak digunakan.

6) Morphological Processing, proses untuk memperoleh informasi yang menyatakan deskripsi dari suatu bentuk pada citra.

7) Segmentation, proses untuk membedakan atau memisahkan objek-objek yang ada dalam suatu citra, seperti memisahkan objek dengan latar belakangnya.

8) Object Recognition, suatu proses yang dilakukan untuk mengenali objek-objek apa saja yang ada dalam suatu citra. 


\section{METODE PENELITIAN}

Peneliti mengambil data foto panoramic di RS Ibnu Sina Gresik. Data yang digunakan dalam penelitian ini sebanyak 10 foto panoramic gigi, akan tetapi peneliti melakukan pengambilan foto panoramic gigi orang sebanyak 20.

Data yang digunakan dalam penelitian ini foto panoramic gigi kaninus. Foto panoramic gigi tersebut dipotong dan diambil yang gigi kaninus. Gigi kaninus, yaitu gigi taring. Peneliti melakukan pemotongan dan pengambilan gigi kaninus pada foto panoramic menggunakan aplikasi photoshop.

Dalam pertama terdapat tahapan digitalisasi, tahap digitalisasi merupakan pengambilan file foto panoramic dalam bentuk softcopy. Cara mengambil file tersebut dengan menscannya. Tahap selanjutnya preposesing citra atau tahap pengolahan citra. Tahapan preposesing citra secara jelas digambarkan dalam Gambar 3.

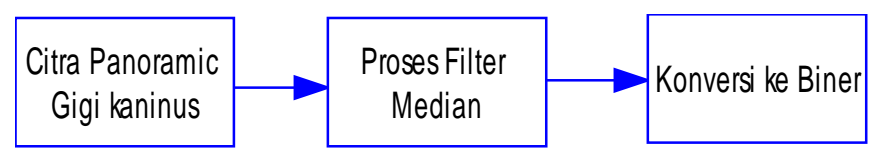

Gambar 3. Tahap Preposesing Citra

Citra foto panoramic yang sudah dalam bentuk softcopy kemudian diedit menggunakan photoshop untuk dijadikan grayscale atau keabu-abuan dan diedit nilai intensitas cahaya dari citra. Setelah selesai diedit menggunakan photoshop selanjutnya diperbaiki menggunakan filter media di aplikasi Matlab. Hasil perbaikan citra tersebut kemudian dikonversi ke bentuk biner dengan metode iterative dan adaptive thresholding serta otsu.

\section{HASIL DAN PEMBAHASAN}

Dalam penelitian ini, untuk melakukan konversi citra ke bentuk biner menggunakan foto panoramic gigi. Foto panoramic gigi yang digunakan dalam perbandingan metode otsu dan iterative thresholding, yaitu kaninus mandibula atau gigi taring bagian bawah. Untuk mendapatkan gigi taring tersebut, peneliti melakukan pemotongan dan pengambilan gigi kaninus madibula dan gigi kaninus maksila.

Gigi kaninus mandibula merupakan gigi taring rahang bawang, yang digunakan peneliti kanan dan kiri. Gigi kaninus maksila merupakan gigi taring rahang atas, juga ada kanan dan kiri, seperti Gambar 4.

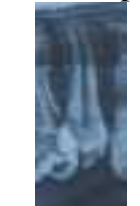

Kiri Atas

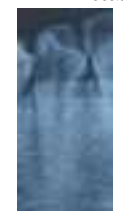

Kiri Bawah

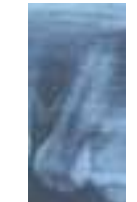

Kanan Atas

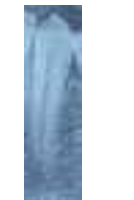

Kanan Bawah

Gambar 4. Gigi Kaninus Potongan Foto Panoramic

Proses pemotongan dan pengambilan gigi kaninus dalam foto panoramic menggunakan cara manual dengan aplikasi Photoshop. Foto yang sudah dipotong merupakan foto berwarna atau RGB. Citra berwarna tersebut selanjutnya dijadikan grayscale atau keabu-abuan. Sesuai dengan nama yang melekat, citra jenis ini menangani gradasi warna hitam dan putih, yang tentu saja menghasilkan efek warna abu-abu. Istilah lain citra keabuan adalah citra grayscale yaitu citra yang nilai pixelnya merepresentasikan derajat keabuan atau instensitas warna putih. Nilai instensitas paling rendah merepresentasikan warna hitam dan nilai intensitas paling tinggi merepresentasikan warna putih. Agar dapat digunakan proses selanjutnya citra dijadikan hitam putih (citra biner) menggunakan aplikasi Matlab. Citra biner adalah citra dengan setiap pixel hanya dinyatakan dengan sebuah nilai dari dua kemungkinan (yaitu nilai 0 dan 1). Nilai 0 menyatakan warna hitam dan nilai 1 menyatakan warna putih.

Dalam mengolah data peneliti menggunakan aplikasi Matlab. Proses pengolahan, peneliti terlebih dahulu mencoba mengubah citra biner dengan metode otsu. Tahap mengubah citra ke biner dengan menggunakan metode otsu, yaitu:

1. Memperbaiki citra menggunakan filter median

2. Mencari nilai batas ambang atau nilai threshold untuk mengubah citra ke bentuk biner menggunakan metode biner 


\section{Mengubah ke bentuk biner}

Hasil dari tahap mengubah bentuk biner dengan metode otsu dalam Gambar 5. Dan sintak dai tahapan ini, yaitu:

\section{Segmen Program 1 Proses Mengubah Citra ke Biner dengan Otsu}

1: $\quad a=$ =imread('Edit/KIA1P.jpg');

2: $\quad m=$ medfilt2(a);

3: $\quad \operatorname{bin}=\operatorname{im} 2 b w(m, g r a y t h r e s h(m))$;

Baris ke-1 digunakan untuk mebaca file citra gigi kaninus panoramic. Baris ke-2 untuk memperbaiki citra dengan filter median. Baris ke-3 untuk mengubah citra ke bentuk biner dengan menggunakan nilai threshold metode otsu. Hasil sintak di atas dalam Gambar 5.

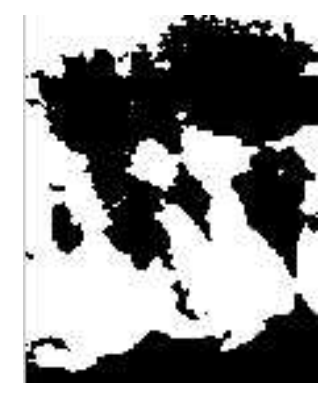

Gambar 5. Hasil Citra Biner Gigi Kaninus Panoramic

Penjelasan dari Gambar 5, yaitu dalam gambar menunjukkan bahwa gigi yang digunakan uji coba adalah gigi kaninus maksila kiri. Warna putih dalam gambar merupakan gigi, sedangkan warna hitam merupakan gusi gigi.

Proses selanjutnya masih melakukan perubahan citra ke bentuk biner dengan algoritma iterative dan adaptive thresholding. Adapun langkahnya:

1. Memperbaiki citra menggunakan filter median

2. Mencari nilai batas ambang atau nilai threshold untuk mengubah citra ke bentuk biner menggunakan metode iterative dan adaptive thresholding

3. Mengubah ke bentuk biner

Hasil dari tahap mengubah bentuk biner dengan metode otsu dalam Gambar 6. Dan sintak dai tahapan ini, yaitu:

Segmen Program 2 Proses Mengubah Citra ke Biner dengan Iteraive dan Adapive Thresholding

1: $\quad a=$ =imread('Edit/KIA1P.jpg');

2: $\quad \mathrm{m}=$ medfilt2(a);

3: $\quad B=$ binaryCitra $(m)$;

Baris ke-1 digunakan untuk mebaca file citra gigi kaninus panoramic. Baris ke-2 untuk memperbaiki citra dengan filter median. Baris ke-3 untuk mengubah citra ke bentuk biner dengan menggunakan nilai threshold metode iterative dan Adaptive Threholding. Hasil sintak di atas dalam Gambar 6.

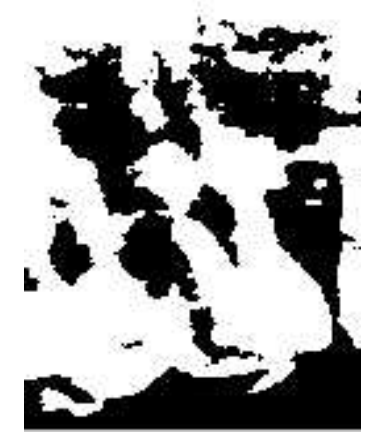

Gambar 6. Hasil Citra Biner Gigi Kaninus Panoramic

Secara keseluruhan, dalam ujicoba mengubah citra ke bentuk biner menghasilkan Gambar 7 dan peneliti akhirnya menggunakan metode yang paling baik, yaitu iterative dan Adaptive Thresholding. 


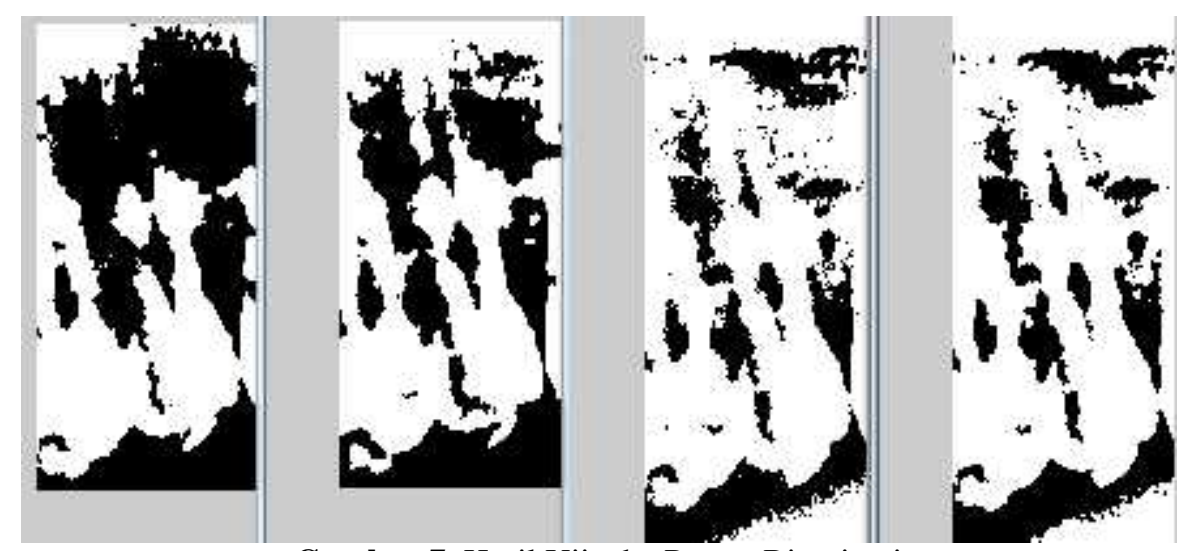

Gambar 7. Hasil Ujicoba Proses Binerisasi

Dari Gambar 7 paling kiri merupakan hasil binerisasi dengan metode otsu, Gambar 7 nomor dua dari kiri merupakan binerisasi menggunakan metode iterative dan daptive thresholding. Sedangkan Gambar 7 nomor dua dari kanan merupakan hasil binerisasi tanpa median filter akan tetapi antara Gambar 7 nomor dua dari kanan dan yang paling kanan kedua citra murni RGB selanjutnya diubah ke bentuk keabu-abuan. Gambar 7 paling kiri hasil binerisasi dengan menggunakan filter median, iterative dan adaptive thresholding.

Dari serangkaian ujicoba proses binerisasi peneliti akhirnya menggunakan metode iterative dan adaptive thresholding dengan citra awal foto gigi kaninus. Gambar 8 merupakan citra awal gigi kaninus panoramic yang diolah sehingga menghasilkan citra biner seperti Gambar 7 nomor dua dari kanan dan paling kanan. Gambar 9 merupakan citra gigi kaninus panoramic yang diolah menggunakan photoshop untuk diubah menjadi keabuabuan selanjutnya dibinerisasi menggunakan Matlab seperti Gambar 7 nomor dua dari kiri dan paling kiri.

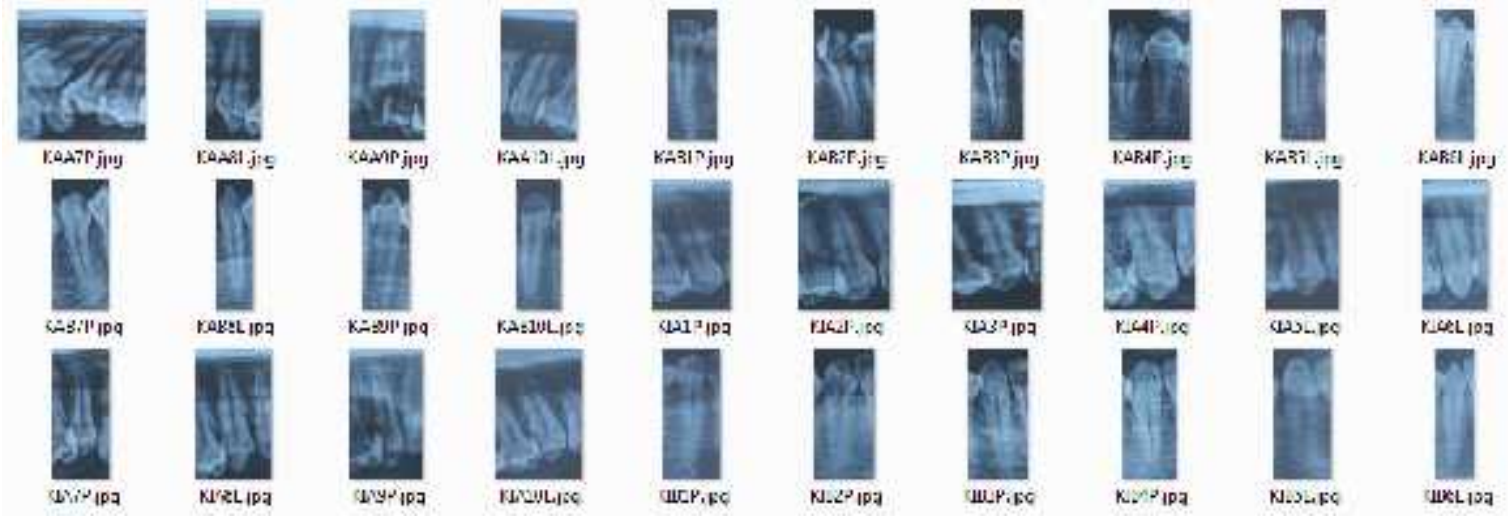

Gambar 8. Citra Awal Gigi Kaninus Panoramic

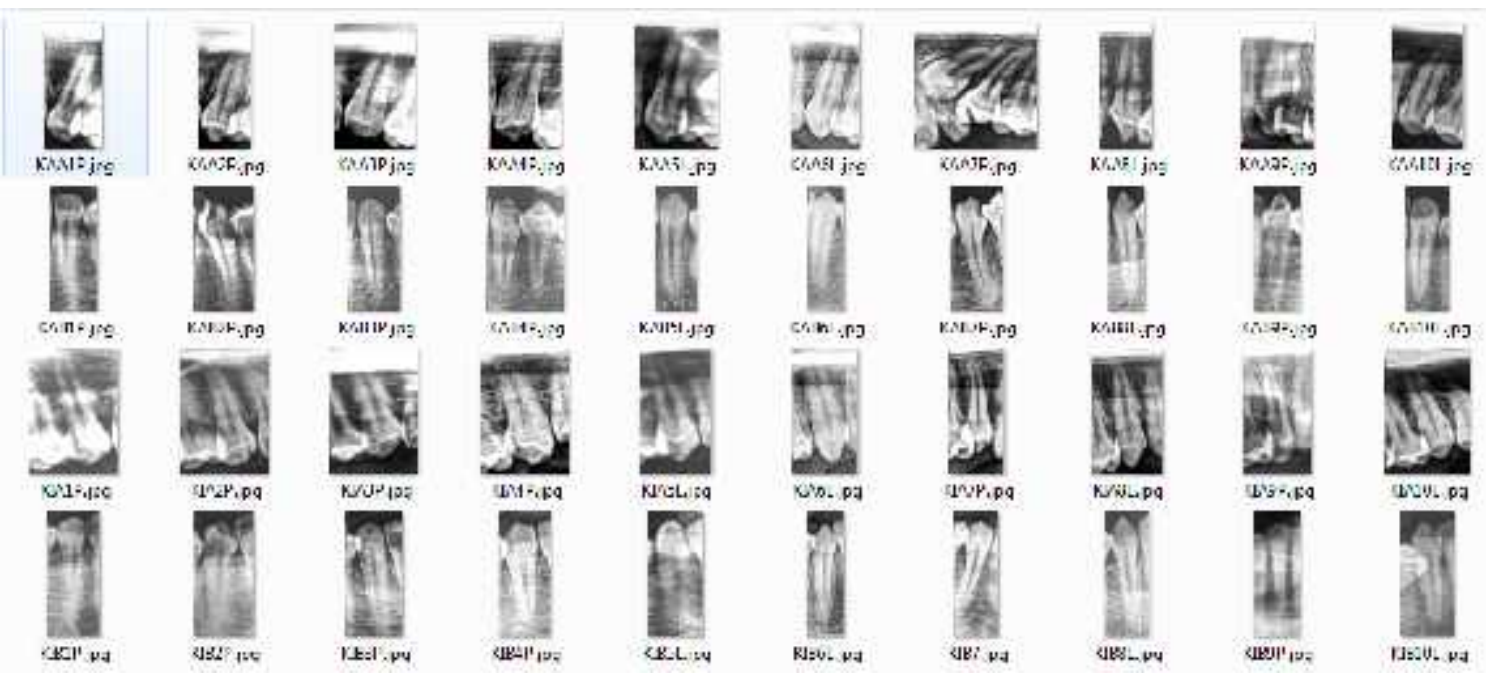

Gambar 9. Citra Gigi Kaninus Panoramic Olahan Photoshop 


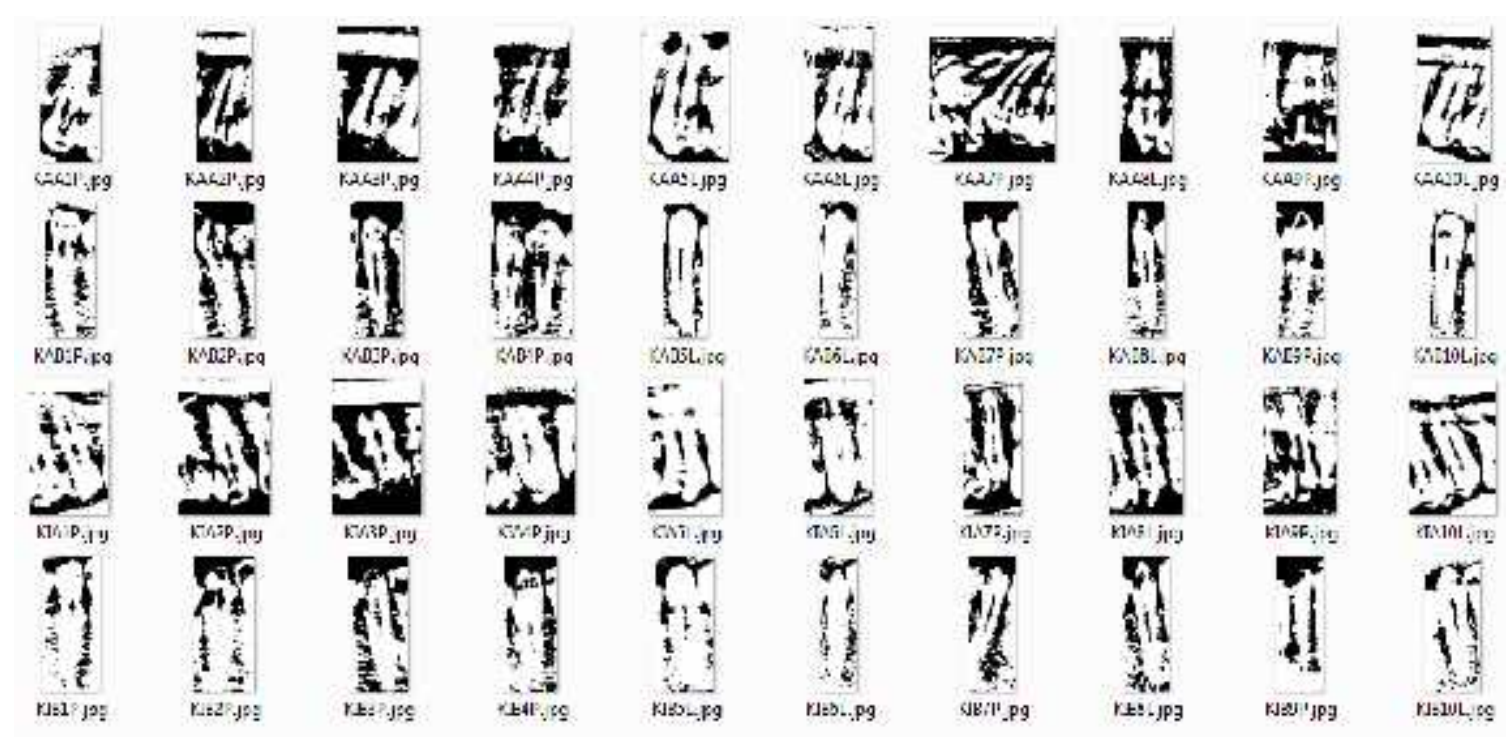

Gambar 10. Hasil Binerisasi dari Citra Awal Gigi Kaninus Panoramic

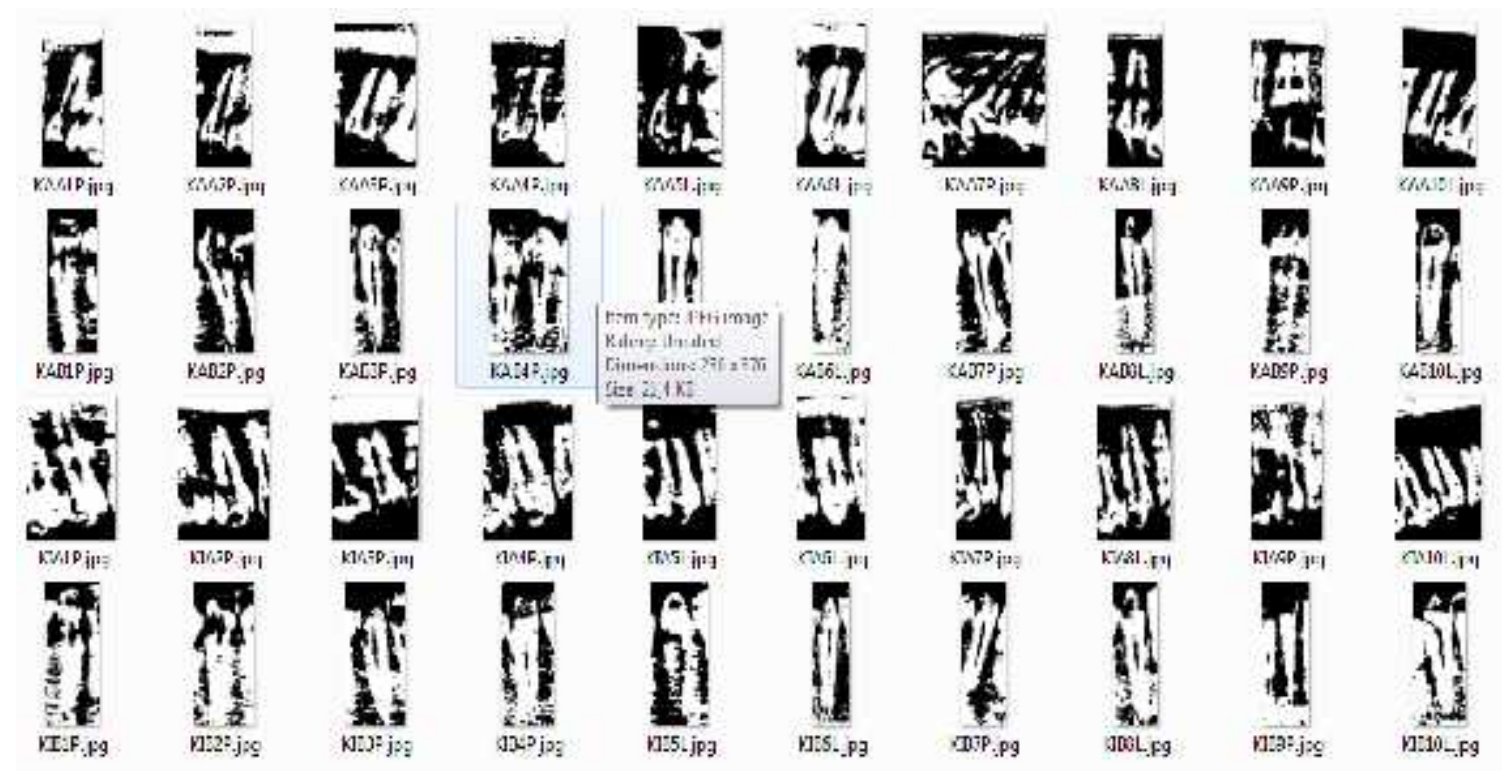

Gambar 11. Citra Biner Gigi Kaninus Panoramic Olahan Photoshop

\section{KESIMPULAN}

Dari beberapa ujicoba dan persiapan pengolahan data, peneliti menyimpulkan:

1) Citra yang diolah terlebih dahulu di photoshop hasilnya lebih baik, karena citra binerisasinya lebih tepat.

2) Citra harus dilakukan perbaikan terlebih dahulu menggunakan filter median, agar nilai intensitas citra merata.

3) Dalam melakukan binerisasi, metode iterative dan adaptive thresholding lebih baik hasilnya.

\section{DAFTAR PUSTAKA}

[1] Itjingningsih W.H.1991. Drg. Anatomi Gigi. Jakarta.

[2] Kasni. 2014. Evaluasi Foramen Mental Berdasarkan Jenis Kelamin Ditinjau sara adiografi Panoramik. Fakultas Kedokteran Ggi Universitas Hasanuddin Makassar.

[3] Lukman, Djohansyah. 2006.Buku Ajar Jilid 2 Ilmu Kedokteran Gigi Forensik. Sagung Seto, Jakarta.

[4] Nehenia, Benindra. 2012.Perkiraan Usia Berdasarkan Metode TCI dan Studi Analisis Histologis Ruang Pulpa pada Usia 9-21 Tahun. Progam Megister Ilmu Kedokteran Gigi Dasar Jakarta. 
[5] Paramaputri, Made Ayu Dani. 2014. Pengaruh Gigi Impaksi Molar Ketiga Rahag Bawah terhadap Ketebalan Angulus Mandibula Berdasarkan Jenis Kelamin. Fakultas Kedokteran Gigi Universitas Mahasaraswati Denpasar. 